\title{
Las elecciones autonómicas andaluzas de 2012 en la prensa nacional: Análisis de la cobertura de $A b c, E l$ Mundo y El País
}

\author{
The Andalusian elections of 2012 in the national press: \\ Analysis of the coverage of $A b c, E l$ Mundo and El País
}

\begin{abstract}
BJ Gómez Calderón [C. V.] [D ORCID] [ G GS] Profesor Contratado Doctor. Facultad de Ciencias de la Comunicación. Universidad de Málaga (España)-bjgomez@uma.es
\end{abstract}

FJ Paniagua Rojano [C. V.] [D ORCID] [ G GS] Profesor Contratado Doctor. Facultad de Ciencias de la Comunicación. Universidad de Málaga (España) - fjpaniagua@uma.es

P Farias Batlle [C. V.] [ $\underline{\text { orCID }}$ [ [ G GS] Profesor Titular de Universidad. Facultad de Ciencias de la Comunicación. Universidad de Málaga (España) - farias@uma.es

\begin{abstract}
s
[ES] Introducción. El artículo analiza la cobertura que los diarios de difusión nacional con edición autonómica (Abc, El Mundo y El País) prestaron a la campaña de las elecciones andaluzas del 25 de marzo de 2012. Objetivos. Determinar similitudes y divergencias en el tratamiento de los comicios entre unas cabeceras y otras, establecer el grado de convergencia de su agenda con la de los partidos contendientes, caracterizar la presencia de los líderes políticos e identificar los frames predominantes. Metodología. Se aplica el análisis de contenido, atendiendo a dieciséis ítems relativos a la ubicación, la producción y el contenido de 497 textos publicados por los tres diarios. Conclusiones. La investigación constata el predominio de temas regionales en la cobertura de la campaña, la escasa presencia de elementos interpretativos y analíticos y la primacía de los encuadres estratégico y de juego en el enfoque de la información.

[EN] Introduction.This article analyses the coverage of the Andalusian elections campaign of 25 March, 2012, by the Andalusian editions of three Spanish national newspapers: Abc, El Mundo and El País. Objectives. To determine the similarities and differences in the treatment given to the elections by these newspapers; to establish the degree of convergence between the agenda of these newspapers and the agenda of the contending parties; to characterise the presence of the political leaders; and to identify the predominant frames. Methods. Content analysis focused on sixteen items related to the location, production features and content of the 497 election news items published by the sample of newspapers. Conclusions. There was a predominance of regional issues in the coverage of the elections campaign; there was a low presence of interpretive and analytical elements; and there was a predominance of strategic and game frames in the coverage of the elections campaign.
\end{abstract}




\section{Keywords}

[ES] Campañas electorales; Andalucía; prensa diaria; agenda-setting; framing.

[EN] Election campaigns; Andalusia; daily press; agenda-setting; framing.

\section{Contents}

[ES] 1. Introducción. 1.1. El estudio de la cobertura de las campañas electorales en los medios. 1.2. Objetivos e hipótesis. 2. Método. 3. Resultados. 3.1. Ubicación. 3.2. Producción. 3.3. Caracterización del contenido. 4. Conclusiones y discusión. 5. Bibliografía. 6. Notas. 7. Fuentes.

[EN] 1. Introduction. 1.1. Study of the media coverage of election campaigns. 1.2. Objectives and hypotheses. 2. Methods. 3. Results. 3.1. Location. 3.2. Production features. 3.3. Characterisation of content. 4. Conclusions and discussion. 5. Bibliography. 6. Notes. 7. Sources.

Traducción de CA Martínez Arcos (Universidad Autónoma de Tamaulipas)

\section{Introducción}

El 25 de marzo de 2012 se celebraban en Andalucía unos comicios que, según todas las encuestas, podían suponer la salida del PSOE de la Presidencia de la Junta después de treinta años de gobierno ininterrumpido. Por vez primera desde 1994, las elecciones autonómicas no coincidían con una convocatoria nacional, algo en lo que se empeñó el presidente de la región, José Antonio Griñán, con el propósito -según todas las interpretaciones- de evitar que la victoria del Partido Popular registrada en las generales de noviembre de 2011 produjera un efecto de contagio en la comunidad andaluza (vid. Rivera, 2012).

Las expectativas de cambio eran grandes, y en medios políticos y periodísticos se daba como seguro el triunfo del aspirante popular, Javier Arenas, que afrontaba su cuarta candidatura a presidente después de haber resultado derrotado en 1994, 1996 y 2008.

Tal y como apunta Colmenarejo (2012), las elecciones llegaban en un contexto de notable desgaste para el PSOE, acuciado por diversos escándalos de corrupción cuya instrucción coincidió en parte con el desarrollo de la campaña, en particular uno, el de los falsos ERE, de repercusiones políticas ineludibles y en el que aparecían implicados varios ex altos cargos de la Junta.

Finalmente, el Partido Popular logró su primera victoria en unos comicios autonómicos andaluces pero el número de escaños alcanzado, 50, quedó lejos de la mayoría absoluta que necesitaba para formar gobierno.

Al PSOE, derrotado aunque por estrecho margen (consiguió 47 diputados), se le abrió la opción de continuar en el poder a través de un pacto con Izquierda Unida, tercera fuerza de la cámara, que dobló su representación, pasando de 6 a 12 escaños, y multiplicó su influencia hasta el punto de entrar en el Ejecutivo regional dos meses después de celebrarse las elecciones [1].

La relativa novedad que supuso la convocatoria en solitario de los comicios, así como la posibilidad del cambio, que parecía real a tenor de las encuestas y del ciclo político imperante en España, concedieron a la campaña un protagonismo mediático inusual, lo cual justifica nuestro interés por analizar la cobertura que le prestó la prensa nacional de referencia. 


\subsection{El estudio de la cobertura de las campañas electorales en los medios}

Desde que en 1972 McCombs y Shaw propusieron la teoría de la agenda-setting para explicar de qué modo influyen los medios de comunicación en la conformación de la opinión pública, su aplicación al estudio de la prensa ha sido intensa y fructífera, sobre todo en relación con el tratamiento de la política y de los procesos electorales. Como apunta Kavanag (1995: 40), los partidos no solo compiten por los votos, sino también por imponer los temas que se abordan durante la campaña: es lo que Norris denomina, con inspiración bélica, la "batalla de las agendas" (1999: 54).

En el proceso de establecimiento de los issues que atraen la atención de la audiencia, cada medio desempeña un papel diferenciado. Coincidimos con Almaguer (2010: 204) en que "son los periódicos los primeros promotores en la organización de una agenda, definiendo ampliamente el ámbito del interés público".

No obstante, según Benton y Frazier (en Paniagua y Gómez, 2006: 283), en una campaña electoral los diarios resultan más efectivos durante los primeros días, pero a medida que se acerca la jornada de votación, es la televisión el medio que logra imponer su repertorio de temas. Aun así, en niveles profundos de conocimiento, la prensa es el canal determinante, pues los ciudadanos recuerdan mejor los asuntos que se han tratado por escrito que los que se han difundido solo a través de medios audiovisuales.

Si bien la investigación ha ido enriqueciendo el concepto de agenda-setting con elementos que trascienden el mero cómputo de issues, atendiendo también al modo en que se transmiten las prioridades temáticas (el denominado "segundo nivel de la agenda-setting", vid. Rodríguez, 2004: 15), en las últimas décadas el análisis del discurso periodístico ha incorporado un constructo especialmente feraz, complementario del de McCombs y Shaw: el de frame, marco o encuadre.

El framing presta atención no a la cantidad de temas que abordan los medios sino a sus atributos, a los aspectos concretos que se destacan de ellos y a las valoraciones que se deslizan sobre el contenido de las noticias (Martín y Berganza, 2001: 60; Novo, 2007: 45). Entendemos el encuadre como "la idea central organizadora del contenido de las informaciones que provee de contexto y sugiere que en un tema se está usando la selección, énfasis, exclusión y elaboración" (Tankard, en Berganza 2008: 26). Como apuntan Scheufele y Tewksbury (2007: 12), el framing "is a necessary tool to reduce the complexity of an issue, given the constraints of their respective media related to news holes and airtime" [2].

En el ámbito de la información electoral, hay determinados frames que predominan sobre el resto (Jackson, 2011). El principal es el estratégico, "aquel que centra la cobertura en quién gana y quién pierde; está dirigido por el lenguaje de la guerra y de los juegos; predominan las menciones a los actores, a las críticas y a las audiencias; pone énfasis en el estilo y percepciones del candidato; y da una gran importancia a los sondeos", de acuerdo con la definición de Capella y Jamieson (en Berganza, 2008a: 124). Estrechamente relacionado con él, hasta el punto de que hay autores que los consideran intercambiables, se encuentra el enfoque de juego, que concibe la política como una competición entre candidatos. En ambos frames está muy presente la idea de conflicto, puesta de relieve ya en numerosos análisis de la cobertura de procesos electorales, v. gr. Berganza, 2008a.

Frente a estos encuadres, se identifica el de issues o de cobertura temática, focalizado en el contenido del discurso que transmiten los actores públicos en lugar de en sus actitudes o en su actividad. Se trataría de un "enfoque informativo, donde se otorga a las audiencias conocimiento para formar sus propias actitudes y opiniones políticas" (Berganza, 2008a: 124). Como puede imaginarse, las implicaciones de la adopción del encuadre estratégico frente al temático pueden ser importantes para el público si este decide la orientación de su voto solo en función de lo que los medios difunden. 
En España, los estudios más recientes sobre la cobertura de procesos electorales abordan, en una primera fase, el establecimiento de la agenda, destacando, en todos los casos, la convergencia entre el repertorio de temas enfatizado por los partidos políticos y los asuntos a los que atiende la prensa, así los de Farré (1999), sobre el comportamiento de las cabeceras regionales durante los comicios autonómicos vascos; Semetko y Canel (1997) y Martín y Berganza (2001), que analizan el tratamiento de las elecciones generales de 1996; Canel, Benavides y Echart (2003) y Benavides y Canel (2003), que se ocupan de las de 2000; y Paniagua y Gómez (2006), que hacen lo propio con las de 2004.

En la misma línea, aunque ya integrando elementos contemplados en el segundo nivel de la agendasetting, se sitúan los trabajos de Zugasti y Lafuente (2010) y Zurutuza y García (2012) sobre la campaña de las legislativas europeas de 2009, con especial atención al protagonismo de los líderes.

Y de acuerdo con la popularización del análisis del framing en el ámbito anglosajón, en los últimos años algunos autores se han ocupado de los enfoques predominantes en los medios españoles, v. gr. Berganza (2008a, 2008b), a partir de las informaciones publicadas sobre los dos últimos comicios europeos; y Berganza, De Miguel y Chaparro (2011), que trazan una detallada comparativa entre los encuadres de los diarios de pago y los gratuitos ante las elecciones generales de 2008.

\subsection{Objetivos e hipótesis}

Nuestra investigación perseguía varios objetivos de diverso alcance:

- En primer lugar, nos interesaba diseccionar el tipo de cobertura que cada diario de difusión nacional con edición andaluza ( $A b c, E l$ Mundo y El País) prestó a la campaña para las elecciones del 25 de marzo, con el propósito de determinar sus similitudes y eventuales divergencias.

- En segundo lugar, considerábamos relevante analizar la agenda temática trasladada por los distintos rotativos, para establecer su grado de convergencia con la de los partidos en liza. No en vano, toda campaña asiste a un proceso de enfatización de issues por parte de los candidatos, que "intentan transmitir a los ciudadanos sus prioridades políticas seleccionando cuidadosamente los temas de los que les interesa que se hable" (Novo, 2007: 46).

- También nos propusimos caracterizar la presencia mediática de los protagonistas de los comicios, en especial, los líderes de las principales formaciones, así como los mecanismos a través de los cuales los medios expresaron su toma de posición frente a ellos. Como señalan Zurutuza y García (2012), es característico de los procesos electorales contemporáneos "el elevado grado de personalización", fruto del influjo de la política estadounidense. La cobertura informativa se focaliza cada vez más en el aspirante a gobernar y en sus atributos, algo que es a la vez causa y efecto de la abundancia de actos mediáticos protagonizados por los candidatos.

- Finalmente, pretendíamos identificar los encuadres o frames predominantes en el tratamiento de la campaña, diferenciando entre los enfoques estratégicos y de juego, que podemos considerar complementarios, y el temático, de orientación informativa.

En línea con estos objetivos, planteamos tres hipótesis para su verificación o refutación:

Hipótesis 1: Dado que las elecciones autonómicas de 2012 se celebraron en fecha distinta de las nacionales, en contra de lo que había sido habitual en Andalucía durante las dos últimas décadas, consideramos probable que en la agenda de los medios se detectara una primacía clara de temas regionales frente a asuntos de índole nacional.

Hipótesis 2: De acuerdo con la tendencia al reduccionismo competitivo que caracteriza a la información política en periodo electoral (cf. Berganza, 2008a y 2008b; Berganza, De Miguel y 
Chaparro, 2009; y Jackson, 2011, entre otros), supusimos que los contenidos suministrados por los medios no abundarían en elementos interpretativos y analíticos que pudieran servir de orientación al lector.

Hipótesis 3: Por la misma razón que en el caso anterior, avanzamos que los frames más habituales en la crónica de la campaña serían el estratégico y el de juego, quedando el temático relegado a una posición marginal.

\section{Método}

Para llevar a cabo el estudio, se seleccionaron los tres diarios nacionales que disponen de edición regional en Andalucía: Abc, El Mundo y El País. De ellos se extrajeron todos los textos relacionados con las elecciones autonómicas publicados entre el 9 de marzo - día de inicio de la campaña- y el 25 de marzo -fecha de los comicios-. El corpus final quedó integrado por 497 unidades, a las que se aplicó una ficha compuesta según los estándares del análisis de contenido.

La elección de esta metodología vino propiciada por su idoneidad para afrontar investigaciones cuantitativas sobre textos escritos, una práctica de larga tradición en el ámbito de la Periodística. El análisis de contenido permite el establecimiento de inferencias fiables sobre el contexto de las noticias (Krippendorff, 2002: 28) y sobre sus condiciones de producción y recepción. Asimismo, su utilidad para recopilar, procesar y evaluar grandes cantidades de información (Sánchez, 2005: 214) y su frecuente utilización en la descripción de los componentes de los mensajes mediáticos (Igartua, 2006: 194), hacían de él el método de indagación más apropiado para nuestro trabajo.

La ficha de análisis aplicada integraba categorías tanto formales como de contenido, agrupadas en tres campos:

a) Ubicación: sección, emplazamiento y extensión.

b) Producción: autoría, género, incorporación de elementos gráficos, fuentes utilizadas y actos que originan las informaciones.

c) Caracterización del contenido: tipo de titulares, tipo de contenido, temas abordados, protagonismo en titulares y en elementos gráficos, actividades destacadas de los protagonistas, encuadres y posicionamiento del medio o el autor.

Los tres diarios escogidos gozan de amplia circulación en la comunidad autónoma andaluza. De acuerdo con los datos facilitados por la Oficina de Control de la Difusión (OJD) [3], la edición regional de $A b c$ vendió 47.309 ejemplares de media al día entre julio de 2011 y junio de 2012. El País, por su parte, difundió 33.917 copias en el mismo periodo, y El Mundo, 31.952. Ninguna cabecera local o provincial editada en la región supera estas cifras, a las que solo se aproximan Ideal, de Granada (26.527 ejemplares), y Sur, de Málaga (23.481), lo cual da una idea del peso que los rotativos nacionales tienen en la dieta mediática de los andaluces, y justifica el interés por analizar el tratamiento que otorgaron a las autonómicas de 2012.

\section{Resultados}

Las elecciones del 25 de marzo acapararon, como es lógico, el interés de las ediciones regionales de los periódicos seleccionados, si bien tanto en su disposición como en la cobertura que se les prestó se han detectado diferencias entre unos medios y otros, de significación variada.

$A b c$ es la cabecera que más textos les dedica, 197, por 155 de El Mundo y 140 de El País. En los tres casos, las crónicas sobre los actos de campaña abren la sección, que se completa con elementos 
diversos: El País suele incluir un reportaje a fondo sobre algún aspecto destacado de la realidad andaluza (educación, cultura, medio ambiente, turismo...), una columna de opinión y entrevistas con expertos no vinculados a la política. El Mundo, aunque también publica análisis sobre la situación de la comunidad autónoma, incorpora más artículos de opinión. Y Abc ofrece cada día reportajes en los que pone el énfasis en la "metacobertura" de la campaña [4], con especial referencia a la actividad de los candidatos en las redes sociales, además de incluir el artículo de su director, Fernando del Valle, y una entrevista a personalidades del ámbito empresarial o cultural.

\subsection{Ubicación}

La mayoría de las unidades analizadas, el 85,2 por ciento, aparecen en la sección de Andalucía, con índices que oscilan entre el 79,4 (El Mundo) y el 97,9 por ciento (El País) [tabla 1]. No obstante, en el caso del primero, un 7,7 por ciento corresponde a piezas agrupadas bajo el epígrafe "Otras voces", que acoge la opinión de las distintas ediciones territoriales del periódico.

$A b c$ es el medio que con mayor frecuencia se ocupa de las elecciones andaluzas fuera de la sección regional, concretamente en "Opinión". Los comentaristas nacionales les prestan una atención considerable, que va incrementándose a medida que se acerca el 25 de marzo.

\begin{tabular}{|c|c|c|c|c|c|c|c|c|}
\hline \multicolumn{9}{|l|}{ Tabla 1. Secciones } \\
\hline & \multicolumn{2}{|c|}{$A b c$} & \multicolumn{2}{|c|}{ ElMundo } & \multicolumn{2}{|c|}{ ElPaís } & \multicolumn{2}{|c|}{ Tres diarios } \\
\hline & Total & $\%$ & Total & $\%$ & Total & $\%$ & Total & $\%$ \\
\hline Andalucía & 159 & 80,7 & 123 & 79,4 & 137 & 97,9 & 419 & 85,2 \\
\hline Opinión & 33 & 16,8 & 12 & 7,7 & 1 & 0,7 & 46 & 9,3 \\
\hline Opinión Andalucía & & & 18 & 11,6 & & & 18 & 3,7 \\
\hline Nacional & 5 & 2,5 & 1 & 0,6 & 2 & 1,4 & 8 & 1,6 \\
\hline Última & & & 1 & 0,6 & & & 1 & 0,2 \\
\hline Total & 197 & 100,0 & 155 & 100,0 & 140 & 100,0 & 492 & 100,0 \\
\hline
\end{tabular}

En cuanto al emplazamiento de los textos, hay divergencias notables. El País, que disponía entonces de un cuadernillo independiente para Andalucía, sitúa cada día las elecciones abriendo sección, al igual que $A b c$, mientras que $E l$ Mundo apuesta casi siempre por ofrecer en primer lugar las informaciones referidas a los escándalos de corrupción en los que aparece implicado el Gobierno de la Junta, como el caso Invercaria y, sobre todo, el de los falsos ERE [5].

Los progresos de la investigación de la juez Mercedes Alaya y las revelaciones de los cargos imputados - con el ex director general de Empleo, Francisco José Guerrero, como cabeza visible de la trama- abren cada día la sección de Andalucía de El Mundo presididos por el lema "Políticos bajo sospecha". De la generosidad del rotativo en el tratamiento de la corrupción da muestra el total de artículos que le dedica, 85; en doce ocasiones, además, las revelaciones cuentan con llamada en la portada del periódico. Y cualquier indicio de comportamiento poco ético que afecte a miembros del Partido Socialista (v. gr., "El Parque Tecnoalimentario de Vélez-Málaga pagó un máster a la hija del consejero Plata", 23/03/2012), ocupa un lugar más destacado que la actualidad de la campaña.

En parámetros similares se sitúa $A b c$, que, sin restar protagonismo a la contienda electoral, suministra abundante información sobre los escándalos del Ejecutivo autonómico en hasta 50 piezas que, con frecuencia, abren la sección de Nacional y el apartado de fotonoticias "Enfoque".

Estas cifras contrastan con las de El País, mucho más comedido en su cobertura del proceso judicial de los ERE, al que dedica solo 23 noticias durante todo el periodo. 


\section{Revista Latina de Comunicación Social \# 068 - Páginas 268 a 289 \\ Investigación financiada | DOI: 10.4185/RLCS-2013-977| ISSN 1138-5820|| Año 2013}

Las elecciones rara vez figuran en portada, donde obtienen un exiguo 2,8 por ciento de incidencias, casi todas correspondientes a El Mundo [tabla 2]. Y en cuanto a las páginas impares, las más destacadas desde el punto de vista informativo, predominan solo en $A b c$ (64,5 por ciento de textos).

\begin{tabular}{|c|c|c|c|c|c|c|c|c|}
\hline \multicolumn{9}{|c|}{ Tabla2. Emplazamiento } \\
\hline & \multicolumn{2}{|c|}{$A b c$} & \multicolumn{2}{|c|}{ ElMundo } & \multicolumn{2}{|c|}{ ElPaís } & \multicolumn{2}{|c|}{ Tres diarios } \\
\hline & $\begin{array}{c}\text { Total } \\
(n=197)\end{array}$ & $\%$ & $\begin{array}{c}\text { Total } \\
(n=155)\end{array}$ & $\%$ & $\begin{array}{c}\text { Total } \\
(n=140)\end{array}$ & $\%$ & $\begin{array}{c}\text { Total } \\
(n=492)\end{array}$ & $\%$ \\
\hline Página impar & 127 & 64,5 & 63 & 40,6 & 67 & 47,9 & 257 & 52,2 \\
\hline Página par & 77 & 39,1 & 94 & 60,6 & 71 & 50,7 & 242 & 49,2 \\
\hline Derecha & 77 & 39,1 & 15 & 9,7 & 17 & 12,1 & 109 & 22,2 \\
\hline Izquierda & 51 & 25,9 & 12 & 7,7 & 5 & 3,6 & 68 & 13,8 \\
\hline Parte superior & 102 & 51,8 & 103 & 66,5 & 100 & 71,4 & 305 & 62,0 \\
\hline Parte inferior & 47 & 23,9 & 41 & 26,5 & 40 & 28,6 & 128 & 26,0 \\
\hline Portada & 3 & 1,5 & 9 & 5,8 & 2 & 1,4 & 14 & 2,8 \\
\hline Portadilla & 25 & 12,7 & 4 & 2,6 & 32 & 22,9 & 61 & 12,4 \\
\hline
\end{tabular}

Finalmente, el espacio que ocupan las noticias resulta más generoso en El Mundo y El País, ya que en torno al 50 por ciento de las piezas de ambos rotativos se presenta a cinco columnas [tabla 3].

\begin{tabular}{|l|c|c|c|c|c|c|c|c|}
\hline \multicolumn{2}{|c|}{ Tabla 3. Número de columnas } \\
\hline \multirow{2}{*}{} & \multicolumn{2}{|c|}{ Abc } & \multicolumn{2}{c|}{ ElMundo } & \multicolumn{2}{c|}{ EIPaís } & \multicolumn{2}{c|}{ Tres diarios } \\
\cline { 2 - 9 } & Total & $\%$ & Total & $\%$ & Total & $\%$ & Total & $\%$ \\
\hline $\mathbf{1}$ & 42 & 21,3 & 32 & 20,6 & 15 & 10,7 & 89 & 18,1 \\
\hline $\mathbf{2}$ & 45 & 22,8 & 10 & 6,5 & 1 & 0,7 & 56 & 11,4 \\
\hline $\mathbf{3}$ & 33 & 16,8 & 17 & 11,0 & 6 & 4,3 & 56 & 11,4 \\
\hline $\mathbf{4}$ & 38 & 19,3 & 21 & 13,5 & 30 & 21,4 & 89 & 18,1 \\
\hline $\mathbf{5}$ & 12 & 6,1 & 70 & 45,2 & 72 & 51,4 & 154 & 31,3 \\
\hline $\mathbf{6}$ & 19 & 9,6 & 2 & 1,3 & 6 & 4,3 & 27 & 5,5 \\
\hline $\mathbf{7}$ & & & & & 2 & 1,4 & 2 & 0,4 \\
\hline $\mathbf{8}$ & 7 & 3,6 & & & & & 7 & 1,4 \\
\hline $\mathbf{1 0}$ & 1 & 0,5 & 3 & 1,9 & 5 & 3,6 & 9 & 1,8 \\
\hline $\mathbf{1 4}$ & & & & & 3 & 2,1 & 3 & 0,6 \\
\hline Total & 197 & 100,0 & 155 & 100,0 & 140 & 100,0 & 492 & 100,0 \\
\hline
\end{tabular}

\subsection{Producción}

La cobertura de una campaña electoral requiere el despliegue de corresponsales que se integren en las caravanas de los partidos y ofrezcan, con puntualidad informativa y algo de impronta personal, la crónica diaria de la actividad de los candidatos. Los tres medios seleccionados disponen de enviados especiales que siguen en exclusiva a José Antonio Griñán y a Javier Arenas; en el caso de Diego Valderas, cabeza de lista de IU, solo El Mundo opta por una firma fija, de ahí que el rotativo dirigido por Pedro J. Ramírez sea el que presente mayor número de textos adscritos a corresponsales [tabla 4].

Los redactores de plantilla son los responsables de la mayoría de las piezas en $A b c(42,6$ por ciento) y El País (56,4 por ciento). 


\begin{tabular}{|l|c|c|c|c|c|c|c|c|}
\hline Tabla4. Autoría de los textos & \multicolumn{2}{c|}{ ElMundo } & \multicolumn{2}{c|}{ EIPais } & \multicolumn{2}{c|}{ Tres diarios } \\
\cline { 2 - 9 } & Total & $\%$ & Total & $\%$ & Total & $\%$ & Total & $\%$ \\
\hline Redactor & 84 & 42,6 & 30 & 19,4 & 79 & 56,4 & 193 & 39,2 \\
\hline Corresponsal & 25 & 12,7 & 46 & 29,7 & 26 & 18,6 & 97 & 19,7 \\
\hline Firma (0pinión) & 37 & 18,8 & 44 & 28,4 & 12 & 8,6 & 93 & 18,9 \\
\hline Medio & 30 & 15,2 & 19 & 12,3 & 15 & 10,7 & 64 & 13,0 \\
\hline Sin firma & 21 & 10,7 & 16 & 10,3 & 1 & 0,7 & 38 & 7,7 \\
\hline Agencias & & & & & 7 & 5,0 & 7 & 1,4 \\
\hline Total & 197 & 100,0 & 155 & 100,0 & 140 & 100,0 & 492 & 100,0 \\
\hline
\end{tabular}

En el uso de los géneros periodísticos se aprecian diferencias de calado entre unas cabeceras y otras [tabla 5]. Destaca la abundancia de sueltos y editoriales - hasta 15- que El Mundo dedica a las elecciones andaluzas, así como el amplio número de columnas (58, es decir, el 37,5 por ciento del total de textos publicados), en su mayoría a cargo de comentaristas regionales, entre los que sobresalen José Antonio Gómez Marín, Agapito Maestre, Luis Miguel Fuentes, Rafael Porras y Juan Antonio Rodríguez Tous.

$A b c$ registra un 20,3 por ciento de artículos de opinión, aunque en esta ocasión la autoría corresponde sobre todo a firmas nacionales: Ignacio Camacho, Antonio Burgos, José María Carrascal, Gabriel Albiac y Manuel Martín Ferrand.

Frente a esto, son pocas las columnas identificadas en El País relativas a las elecciones del 25 de marzo, solo 12. Tampoco en la sección de Opinión tienen una presencia reseñable, pues el único artículo aparecido durante las dos semanas analizadas es un suelto de alcance menor sobre la negativa de Javier Arenas a participar en el debate de Canal Sur Televisión.

\begin{tabular}{|l|c|c|c|c|c|c|c|c|}
\hline \multirow{2}{*}{ Tabla5. Género de Ios textos } & \multicolumn{2}{c|}{ ElMundo } & \multicolumn{2}{c|}{ El País } & \multicolumn{2}{c|}{ Tres diarios } \\
\cline { 2 - 10 } & Total & $\%$ & Total & $\%$ & Total & $\%$ & Total & $\%$ \\
\hline Crónica & 71 & 36,0 & 45 & 29,0 & 32 & 22,9 & 148 & 30,1 \\
\hline Noticia & 24 & 12,2 & 35 & 22,6 & 51 & 36,4 & 110 & 22,4 \\
\hline Columna & 36 & 18,3 & 39 & 25,2 & 12 & 8,6 & 87 & 17,7 \\
\hline Entrevista & 17 & 8,6 & 6 & 3,9 & 17 & 12,1 & 40 & 8,1 \\
\hline Reportaje informativo & 21 & 10,7 & 4 & 2,5 & 18 & 12,9 & 40 & 8,1 \\
\hline Fotonoticia & 18 & 9,1 & 1 & 0,6 & & & 19 & 3,9 \\
\hline Reportaje a fondo & 3 & 1,5 & 6 & 3,9 & 5 & 3,6 & 17 & 3,5 \\
\hline Suelto & & & 10 & 6,5 & 1 & 0,7 & 11 & 2,2 \\
\hline Editorial & 3 & 1,5 & 5 & 3,2 & & & 8 & 1,6 \\
\hline Perfil & 2 & 1,0 & & & 3 & 2,1 & 5 & 1,0 \\
\hline Tribuna & 1 & 0,5 & 4 & 2,6 & & & 5 & 1,0 \\
\hline Análisis & 1 & 0,5 & & & 1 & 0,7 & 2 & 0,4 \\
\hline Total & 197 & 100,0 & 155 & 100,0 & 140 & 100,0 & 492 & 100,0 \\
\hline
\end{tabular}

Los textos más destacados de cada edición, en cualquier caso, son las crónicas. Tanto en El País como en El Mundo, los corresponsales ofrecen más análisis y valoración personal que información estricta, reflexionando sobre el desarrollo de la campaña y el estado de ánimo de los candidatos, así como sobre sus expectativas de triunfo. Hay, en este sentido, una labor de metacobertura continuada y una adopción usual de los encuadres estratégicos y de juego, como se verá en el epígrafe 3.3.

$A b c$ y El País cultivan la entrevista en mayor medida que El Mundo, alternando a políticos con personajes del mundo de la empresa o la cultura que ofrecen su particular visión sobre la situación de Andalucía. Y tanto El Mundo como El País publican balances sectoriales de los cuatro últimos años de gobierno socialista en forma de reportajes, aunque con signo editorial distinto: en el primer caso 
no se ahorran críticas a la gestión de Griñán y sus consejeros, mientras que en el segundo hay un empeño claro por consignar, junto a errores de bulto, aspectos positivos de la legislatura que termina.

La información electoral se presta a la inclusión de elementos gráficos [tabla 6], en especial fotografías de los candidatos, presentes en una horquilla que va del 67,5 por ciento de los textos de $A b c$ al 78,6 de El País. Este último recurre también a gráficos y tablas en un 13,6 por ciento de artículos, cuando el contenido se centra en el análisis de la situación de la comunidad autónoma.

\begin{tabular}{|c|c|c|c|c|c|c|c|c|}
\hline & \multicolumn{2}{|c|}{$A b c$} & \multicolumn{2}{|c|}{ ElMundo } & \multicolumn{2}{|c|}{ ElPaís } & \multicolumn{2}{|c|}{ Tres diarios } \\
\hline & $\begin{array}{c}\text { Total } \\
(n=197)\end{array}$ & $\%$ & $\begin{array}{c}\text { Total } \\
(n=155)\end{array}$ & $\%$ & $\begin{array}{c}\text { Total } \\
(n=140)\end{array}$ & $\%$ & $\begin{array}{c}\text { Total } \\
(n=492)\end{array}$ & $\%$ \\
\hline Fotografía & 121 & 61,4 & 83 & 53,5 & 91 & 65,0 & 295 & 60,0 \\
\hline Caricatura & 7 & 3,6 & 14 & 9,0 & 16 & 11,4 & 37 & 7,5 \\
\hline Gráfico & 4 & 2,0 & 5 & 3,2 & 13 & 9,3 & 22 & 4,5 \\
\hline Tabla & & & 3 & 1,9 & 6 & 4,3 & 9 & 1,8 \\
\hline $\begin{array}{l}\text { Total de textos con } \\
\text { elementos gráficos }\end{array}$ & 103 & 67,5 & 101 & 65,2 & 110 & 78,6 & 314 & 69,9 \\
\hline
\end{tabular}

Las fuentes utilizadas a lo largo de la campaña [tabla 7] muestran un perfil bien definido: mayoría de políticos (47,4 por ciento de casos) identificados con nombres y apellidos (55,9 por ciento). Llama la atención que el uso de las fuentes reservadas sea mínimo, pues solo se recurre a ellas en un 2,8 por ciento de las piezas. En un ámbito con pocas disonancias, destaca únicamente el interés de El País por recabar la opinión de profesionales y expertos (15 por ciento de incidencias).

\begin{tabular}{|l|c|c|c|c|c|c|c|c|}
\hline \multirow{2}{*}{ Tabla7. Fuentes } & \multicolumn{9}{|c|}{ Abc } & \multicolumn{2}{c|}{ EIMundo } & \multicolumn{2}{c|}{ EIPaís } & \multicolumn{2}{c|}{ Tres diarios } \\
\cline { 2 - 10 } & $\begin{array}{c}\text { Total } \\
(\mathbf{n = 1 9 7 )}\end{array}$ & $\%$ & $\begin{array}{c}\text { Total } \\
(\mathbf{n = 1 5 5 )}\end{array}$ & $\%$ & $\begin{array}{c}\text { Total } \\
(\mathbf{n = 1 4 0 )}\end{array}$ & $\%$ & $\begin{array}{c}\text { Total } \\
(\mathbf{n = 4 9 2 )}\end{array}$ & $\%$ \\
\hline Única & 78 & 39,6 & 42 & 27,1 & 61 & 43,6 & 181 & 36,8 \\
\hline Múltiple & 47 & 23,9 & 19 & 12,3 & 45 & 32,1 & 111 & 22,6 \\
\hline Registrada & 115 & 58,4 & 57 & 36,8 & 103 & 73,6 & 275 & 55,9 \\
\hline Reservada & 8 & 4,1 & 2 & 1,3 & 4 & 2,9 & 14 & 2,8 \\
\hline Político & 101 & 51,3 & 51 & 32,9 & 81 & 57,9 & 233 & 47,4 \\
\hline Experto & 16 & 8,1 & 8 & 5,2 & 21 & 15,0 & 45 & 9,1 \\
\hline No cualificada & 5 & 2,5 & 1 & 0,6 & 6 & 4,3 & 12 & 2,4 \\
\hline Ninguna & 4 & 2,0 & 7 & 4,5 & 5 & 3,6 & 16 & 3,3 \\
\hline
\end{tabular}

Las actividades de los candidatos focalizan la actualidad de la campaña [tabla 8], si bien un 42,9 por ciento de los textos analizados optan por soslayarlas; en este grupo se encuadran los artículos analíticos y de opinión, además de las informaciones sobre el eventual desenlace de los comicios, la estrategia de los líderes y sus expectativas electorales. Aunque los mítines multitudinarios son el referente noticioso más habitual (29,9 por ciento de casos), también se presta atención a los meetings o encuentros con públicos segmentados (13 por ciento). Otras actuaciones, como los walkabouts y las ruedas de prensa, reciben cobertura solo de forma esporádica.

Mención aparte merece el consabido debate televisado, que suele animar la campaña en los días previos e inmediatamente posteriores a su emisión, y que en este caso organizó Canal Sur únicamente con los cabezas de lista de PSOE e IU, ya que Javier Arenas se negó a comparecer, arguyendo la supuesta parcialidad del ente autonómico en el trato informativo dispensado al Partido Popular. 


\begin{tabular}{|l|c|c|c|c|c|c|c|c|}
\hline Tabla 8. Actividades de los protagonistas & \multicolumn{2}{c|}{ ElMundo } & \multicolumn{2}{c|}{ EIPais } & \multicolumn{2}{c|}{ Tres diarios } \\
\cline { 2 - 9 } & $\begin{array}{c}\text { Total } \\
(\mathbf{n = 1 9 7 )}\end{array}$ & $\%$ & $\begin{array}{c}\text { Total } \\
(\mathbf{n = 1 5 5 )}\end{array}$ & $\%$ & $\begin{array}{c}\text { Total } \\
(\mathbf{n}=\mathbf{1 4 0})\end{array}$ & $\begin{array}{c}\text { Total } \\
(\mathbf{n}=\mathbf{4 9 2})\end{array}$ & $\%$ \\
\hline Mitin & 58 & 29,4 & 44 & 28,4 & 45 & 32,1 & 147 & 29,9 \\
\hline Meeting & 31 & 15,7 & 25 & 16,1 & 8 & 5,7 & 64 & 13,0 \\
\hline Walkabout & 15 & 7,6 & 8 & 5,2 & 4 & 2,9 & 27 & 5,5 \\
\hline Rueda de prensa & 4 & 2,0 & 10 & 6,5 & 9 & 6,4 & 23 & 4,7 \\
\hline Debate televisivo & 3 & 1,5 & 7 & 4,5 & 3 & 2,1 & 13 & 2,6 \\
\hline Encuesta & 6 & 3,0 & 6 & 3,9 & 1 & 0,7 & 13 & 2,6 \\
\hline Acto oficial & 2 & 1,0 & 5 & 3,2 & 1 & 0,7 & 8 & 1,6 \\
\hline $\begin{array}{l}\text { Actividad en } \\
\text { redes sociales }\end{array}$ & 1 & 0,5 & 6 & 3,9 & & & 7 & 1,4 \\
\hline Canvassing & 4 & 2,0 & 1 & 0,6 & & & 5 & 1,0 \\
\hline Carta & 1 & 0,5 & 1 & 0,6 & & & 2 & 0,4 \\
\hline Entrevista & & & 2 & 1,3 & & & 2 & 0,4 \\
\hline Declaraciones & 1 & 0,5 & & & & & 1 & 0,2 \\
\hline Filtración & & & 1 & 0,6 & & & 1 & 0,2 \\
\hline Ninguno & 79 & 40,1 & 60 & 38,7 & 72 & 51,4 & 211 & 42,9 \\
\hline
\end{tabular}

\subsection{Caracterización del contenido}

Las mayores diferencias entre las cabeceras seleccionadas se aprecian en el nivel de contenido. El encuadre predominante en todos los casos es el estratégico, pero la orientación de titulares y cuerpos de texto, así como el tratamiento gráfico de los protagonistas de la campaña, divergen sensiblemente. También hay desviaciones en el repertorio de issues abordados, pues los tres diarios se esfuerzan por acentuar aquellos temas que mejor encajan con su línea editorial, al tiempo que oscurecen los asuntos menos beneficiosos para las formaciones a las que tácita o explícitamente apoyan.

El enfoque de los titulares [tabla 9] arroja ya proporciones disímiles: mientras que $A b c$ mantiene el estilo informativo en el 50,8 por ciento de los artículos, El País opta de modo frecuente por la interpretación (el 30,7 por ciento de sus títulos se presentan reportajeados). La opinión, sin embargo, se desliza con mayor frecuencia en los encabezamientos del diario de Vocento y en El Mundo, superando en ambos casos el 20 por ciento de piezas, de carácter tanto argumentativo como interpretativo e incluso informativo.

\begin{tabular}{|l|c|c|c|c|c|c|c|c|}
\hline Tabla 9. Tipo de titulares & \multicolumn{2}{|c|}{ Abc } & \multicolumn{2}{c|}{ ElMundo } & \multicolumn{2}{c|}{ EIPais } & \multicolumn{2}{c|}{ Tres diarios } \\
\cline { 2 - 9 } & Total & $\%$ & Total & $\%$ & Total & $\%$ & Total & $\%$ \\
\hline Informativo & 100 & 50,8 & 61 & 39,4 & 50 & 35,7 & 211 & 42,9 \\
\hline Interpretativo & 24 & 12,2 & 30 & 19,4 & 43 & 30,7 & 97 & 19,7 \\
\hline Opinativo & 41 & 20,8 & 32 & 20,6 & 6 & 4,3 & 79 & 16,1 \\
\hline Cita literal & 23 & 11,7 & 14 & 9,0 & 26 & 18,6 & 63 & 12,8 \\
\hline Temático & 9 & 4,6 & 18 & 11,6 & 15 & 10,7 & 42 & 8,5 \\
\hline Total & 197 & 100,0 & 155 & 100,0 & 140 & 100,0 & 492 & 100,0 \\
\hline
\end{tabular}

Precisamente por su estilo propio del reportaje, los titulares de El País revelan la preponderancia de los encuadres estratégico y de juego en la elaboración de los textos, v. gr. "La campaña más reñida" (9/03/2012), "Subidos en el carrusel de las encuestas" (10/03/2012), "De la mano para frenar al PP" 
(14/03/2012) o "Todos contra la mayoría de Arenas" (20/03/2012). El Mundo adopta el mismo enfoque en titulares como "El PSOE 'reinicia' la campaña electoral para recortar distancias" (12/03/2012), “Griñán se resiste a verse perdedor en las encuestas" (17/03/2012) o "Griñán apura la recta final de la campaña con <todo el pescado vendido>" (22/03/2012).

La metáfora deportiva o de horse race, tan habitual en la crónica de enfrentamientos políticos (Almazán y Villarejo, 1998: 106; Humanes, 2009: 108), asoma aquí con fuerza para situar al lector ante un escenario conocido: el de la carrera, el del sprint por alcanzar al que va en cabeza, el del vencedor y el vencido.

El Mundo reserva el encuadre informativo para dar cuenta de la actividad electoral de Javier Arenas, y opta por un estilo interpretativo e incluso opinativo cuando se ocupa del PSOE: "Canal Sur, erre que erre: ahora mete al PP en el caso Malaya" (9/03/2012), "Los sondeos hacen mella en la campaña del PSOE pese al forzado optimismo de Griñán" (19/03/2012). El tono contrasta con el de las crónicas de la campaña 'popular', presididas habitualmente por titulares temáticos: "Arenas quiere estrenarse en la Junta exigiendo a Rajoy otra financiación" (13/03/2012), "Arenas persevera en la denuncia de la corrupción del PSOE" (15/03/2012), "Arenas convoca al cambio frente al "inmovilismo suicida de Andalucía"” (16/03/2012), "Arenas promete el Gobierno más austero y reformista del país" (20/03/2012).

En cuanto a $A b c$, sus encabezamientos muestran una habitual convergencia con la agenda y el argumentario del PP: "Arenas se planta ante los abusos de la RTVA y renuncia al debate" (10/03/2012), "Arenas reducirá de 200 a 56 la cifra de delegados provinciales" (14/03/2012), "Empleo y austeridad, ejes de las primeras 100 medidas de Arenas" (18/03/2012) o "Arenas anuncia que suprimirá 10.000 teléfonos móviles de la Junta" (20/03/2012). Frente a esto, se registran títulos claramente sesgados como "Un hombre solo" (20/03/2012) o "Contra las encuestas, golpes bajos" (22/03/2012), ambos referidos a Griñán.

En el contenido de los textos [tabla 10] se obtienen también índices desiguales. Predomina, como es lógico, la información, más en El País (75 por ciento de artículos) y Abc $(74,1)$ que en El Mundo $(54,2)$. Pero la proporción de opinión es más abultada en estos dos últimos (21,3 y 37,4 por ciento, respectivamente), pues apuestan por enjuiciar el desarrollo de la campaña con mucha mayor intensidad que el diario del grupo Prisa.

Por lo que respecta a los contenidos analíticos -que tan útiles pueden resultar cuando de decantar el voto se trata, pues ayudan a la reflexión-, es El País la cabecera que más espacio les dedica (15,7 por ciento de piezas).

\begin{tabular}{|l|c|c|c|c|c|c|c|c|}
\hline Tabla 10. Tipo de contenido & \multicolumn{2}{|c|}{ Abc } & \multicolumn{2}{c|}{ ElMundo } & \multicolumn{2}{c|}{ El Pais } & \multicolumn{2}{c|}{ Tres diarios } \\
\cline { 2 - 9 } & Total & $\%$ & Total & $\%$ & Total & $\%$ & Total & $\%$ \\
\hline Información & 146 & 74,1 & 84 & 54,2 & 105 & 75,0 & 335 & 68,1 \\
\hline Opinión & 42 & 21,3 & 58 & 37,4 & 13 & 9,3 & 113 & 23,0 \\
\hline Análisis/balance & 9 & 4,6 & 13 & 8,4 & 22 & 15,7 & 44 & 8,9 \\
\hline Total & 197 & 100,0 & 155 & 100,0 & 140 & 100,0 & 492 & 100,0 \\
\hline
\end{tabular}

Los temas a los que los tres diarios prestan atención [tabla 11] ejemplifican bien tanto la asunción de la agenda de los partidos, en unos casos, como la eventual resistencia a incorporarlos, en otros, además de la tendencia a focalizar el debate reduciendo el repertorio de asuntos tratados. En las 
elecciones de 2012, la campaña estuvo presidida por dos issues impulsados desde el Partido Popular que, de forma global, se impusieron a los de su principal contrincante: el escándalo de los ERE fraudulentos -que venía investigándose desde 2010 y ha continuado su periplo en los juzgados una vez pasados los comicios, ya con mucha menor repercusión mediática- y la inevitabilidad del cambio -que finalmente no se produjo-.

Abc y El Mundo llevan los ERE a titulares y entradillas en un 16,2 y un 14,2 por ciento de textos, respectivamente, por lo general haciéndose eco de las declaraciones de los líderes 'populares' pero también motu proprio, lo cual contrasta con el exiguo 5 por ciento que les dedica El País. La conveniencia y proximidad del cambio en la Presidencia de la Junta centra la atención de los dos primeros diarios en proporciones similares (14,7 y 12,3 por ciento), resistiéndose de nuevo El País a destacarlo (4,3 por ciento de menciones).

El periódico que dirige Javier Moreno contrapone a los leitmotivs de la campaña 'popular' balances amables de la gestión socialista (7,9 por ciento de piezas) y críticas a la política del Gobierno central ( 5 por ciento), en un intento poco exitoso de desplazar el foco territorial de las elecciones más allá del ámbito andaluz.

Se trata, de todos modos, de una estrategia marginal en términos cuantitativos, pues en los comicios de marzo de 2012 el enfoque autonómico se impone con claridad al nacional. Ni siquiera la crisis y el desempleo, los dos asuntos que en mayor medida preocupan a los españoles [6], logran hacerse un hueco relevante en la crónica de la campaña.

\begin{tabular}{|c|c|c|c|c|c|c|c|c|}
\hline \multicolumn{9}{|l|}{ Tabla 11. Tema principal* } \\
\hline & \multicolumn{2}{|c|}{$A b c$} & \multicolumn{2}{|c|}{ EIMundo } & \multicolumn{2}{|c|}{ ElPaís } & \multicolumn{2}{|c|}{ Tres diarios } \\
\hline & $\begin{array}{c}\text { Total } \\
(n=197)\end{array}$ & $\%$ & $\begin{array}{c}\text { Total } \\
(n=155)\end{array}$ & $\%$ & $\begin{array}{c}\text { Total } \\
(n=140)\end{array}$ & $\%$ & $\begin{array}{c}\text { Total } \\
(n=492)\end{array}$ & $\%$ \\
\hline Caso ERE & 32 & 16,2 & 22 & 14,2 & 7 & 5,0 & 61 & 12,4 \\
\hline Cambio & 29 & 14,7 & 19 & 12,3 & 6 & 4,3 & 54 & 11,0 \\
\hline Canal Sur TV & 17 & 8,6 & 12 & 7,7 & 9 & 6,4 & 38 & 7,7 \\
\hline Desarrollo de la campaña & 20 & 10,2 & 9 & 5,8 & & & 29 & 5,9 \\
\hline Encuestas & 8 & 4,1 & 7 & 4,5 & 4 & 2,9 & 19 & 3,9 \\
\hline Balances sectoriales & & & 6 & 3,9 & 11 & 7,9 & 17 & 3,5 \\
\hline Pacto PSOE-IU & 8 & 4,1 & 5 & 3,2 & 1 & 0,7 & 14 & 2,8 \\
\hline Políticas sociales & 12 & 6,1 & 1 & 0,6 & & & 13 & 2,6 \\
\hline Vulneraciones de la Ley Electoral & 4 & 2,0 & 7 & 4,5 & 2 & 1,4 & 13 & 2,6 \\
\hline Propuestas electorales del PP & 5 & 2,5 & 4 & 2,6 & 3 & 2,1 & 12 & 2,4 \\
\hline Crisis & 6 & 3,0 & & & 5 & 3,6 & 11 & 2,2 \\
\hline Paro & 4 & 2,0 & 2 & 1,3 & 5 & 3,6 & 11 & 2,2 \\
\hline Críticas al Gobierno central & & & 3 & 1,9 & 7 & 5,0 & 10 & 2,0 \\
\hline
\end{tabular}

*Solo se recogen aquellos con más de un 2 por ciento de incidencias.

Las propuestas electorales ocupan una posición claramente relegada en la agenda de los tres periódicos. Apenas un 5 por ciento de los textos seleccionados las incluyen, y rara vez como asunto principal, demostrando que el enfoque temático resulta, en esta ocasión, superado por el estratégico.

En un escenario político con fuerte tendencia a la polarización -no olvidemos que solo tres formaciones gozan de representación en la cámara autonómica andaluza desde el año 2008-, la 
presencia informativa de los partidos minoritarios es escasa, de ahí que únicamente un 1,8 por ciento de los artículos se ocupe de ellos. Este fenómeno, no obstante, también ha sido observado en comicios en los que el número de contendientes con posibilidad de obtener escaños es mayor (vid. Farré, 1999; Sampedro y Seoane, 2008), lo cual puede llevar a pensar que la reducción del pluralismo es una cualidad inherente al modelo de cobertura que los medios aplican a cualquier proceso electoral.

Abc y El Mundo abordan con frecuencia los entresijos de la campaña -la denominada "metacobertura"-, sobre todo el primero, que les dedica un 10,2 por ciento de textos, con títulos muy expresivos: "Argucias electorales que no vemos" (10/03/2012), "Cuando el discurso también se enreda" (11/03/2012), "El armario de los candidatos" (13/03/2012), "Movilizando a los "ejércitos"” (16/03/2012) o "Caravanas. De viaje... hasta San Telmo" (18/03/2012).

En El Mundo se recurre a la metacobertura sobre todo para poner en evidencia al líder socialista: "Griñán, el reciclador de discursos" (15/03/2012), "Candidato nuevo, campaña antigua" (16/03/2012). Se trata de un fenómeno, el del análisis sesgado de las estrategias de los partidos, ya detectado en el tratamiento informativo de otros comicios (cf. Humanes, 2009).

\begin{tabular}{|c|c|c|c|c|c|c|c|c|}
\hline \multicolumn{9}{|c|}{ Tabla 12. Protagonista en titular } \\
\hline & \multicolumn{2}{|c|}{$A b c$} & \multicolumn{2}{|c|}{ ElMundo } & \multicolumn{2}{|c|}{ ElPais } & \multicolumn{2}{|c|}{ Tres diarios } \\
\hline & \begin{tabular}{|c|} 
Total \\
$(n=197)$
\end{tabular} & $\%$ & $\begin{array}{c}\text { Total } \\
(n=155)\end{array}$ & $\%$ & $\begin{array}{c}\text { Total } \\
(n=140)\end{array}$ & $\%$ & $\begin{array}{c}\text { Total } \\
(n=492)\end{array}$ & $\%$ \\
\hline José Antonio Griîán & 26 & 13,2 & 22 & 14,2 & 6 & 4,3 & 54 & 11,0 \\
\hline Javier Arenas & 20 & 10,2 & 17 & 11,0 & 16 & 11,4 & 53 & 10,8 \\
\hline Diego Valderas & 9 & 4,6 & 11 & 7,1 & 7 & 5,0 & 27 & 5,5 \\
\hline Mariano Rajoy & 5 & 2,5 & 4 & 2,6 & 2 & 1,4 & 11 & 2,2 \\
\hline Manuel Chaves & 3 & 1,5 & 3 & 1,9 & & & 6 & 1,2 \\
\hline Alfonso Guerra & 1 & 0,5 & 1 & 0,6 & & & 2 & 0,4 \\
\hline Cristóbal Montoro & & & 1 & 0,6 & 1 & 0,7 & 2 & 0,4 \\
\hline J.M. Sánchez Gordillo & & & 1 & 0,6 & 1 & 0,7 & 2 & 0,4 \\
\hline Martín de la Herrán & 1 & 0,5 & 1 & 0,6 & & & 2 & 0,4 \\
\hline Pilar González & 1 & 0,5 & & & 1 & 0,7 & 2 & 0,4 \\
\hline RafaelEscuredo & & & 2 & 1,3 & & & 2 & 0,4 \\
\hline RosaDíez & 1 & 0,5 & 1 & 0,6 & & & 2 & 0,4 \\
\hline Cayo Lara & & & 1 & 0,6 & & & 1 & 0,2 \\
\hline FátimaBáñez & & & 1 & 0,6 & & & 1 & 0,2 \\
\hline Felipe González & 1 & 0,5 & & & & & 1 & 0,2 \\
\hline Gaspar Zarrías & & & 1 & 0,6 & & & 1 & 0,2 \\
\hline M. Dolores de Cospedal & & & 1 & 0,6 & & & 1 & 0,2 \\
\hline Carme Chacón & & & & & 1 & 0,7 & 1 & 0,2 \\
\hline Alfredo. P. Rubalcaba & & & 1 & 0,6 & & & 1 & 0.2 \\
\hline Mar Moreno & & & & & 1 & 0,7 & 1 & 0,2 \\
\hline Micaela Navarro & & & 1 & 0,6 & & & 1 & 0,2 \\
\hline \begin{tabular}{|l|} 
Ninguno \\
\end{tabular} & 133 & 67,5 & 99 & 63,9 & 108 & 77,1 & 340 & 69,1 \\
\hline
\end{tabular}

El grado de personalización de la cobertura de la campaña es elevado, de ahí que un 30,9 por ciento de las piezas analizadas destaquen en titulares a los candidatos [tabla 12], con José Antonio Griñán (11 por ciento) y Javier Arenas $(10,8)$ a la cabeza. Más allá de la preponderancia mediática del individuo sobre el colectivo que este dato confirma, las implicaciones argumentativas de su aparición en los encabezamientos de las noticias no son unívocas; de hecho, el perfil poco favorecedor que habitualmente se ofrece del aspirante del PSOE (por sus débiles expectativas electorales, por soportar 


\section{Revista Latina de Comunicación Social \# 068 - Páginas 268 a 289 Investigación financiada $\mid$ DOI: 10.4185/RLCS-2013-977 | ISSN 1138-5820| $\mid$ Año 2013}

la sombra de la corrupción que planea sobre su Gobierno, incluso por sus discutidas capacidades como secretario general) explica que este sea mucho más citado en Abc y El Mundo que en El País.

El enfoque eminentemente regional de la cobertura de la campaña se refleja también en la limitada presencia de políticos nacionales: solo aparecen destacados en más de una ocasión Mariano Rajoy presentado por unos como aval de victoria, y por otros como aviso sobre las políticas de austeridad que pueden implantarse en Andalucía si el PP logra la mayoría absoluta- y Manuel Chaves -este siempre asociado a los escándalos que le afectan de forma individual o colegiada-.

Parecidos índices se obtienen del análisis de los elementos gráficos que acompañan a los textos de la muestra [tabla 13]. Griñán y Arenas se reparten el 70,8 por ciento de las fotografías, siendo marginal la presencia de otros líderes regionales y nacionales, excepción hecha de Diego Valderas, que registra un 16,1 por ciento de incidencias.

Las connotaciones de las imágenes tienden a reforzar el discurso predominante de cada cabecera. En $A b c$, son frecuentes las instantáneas de Arenas rodeado por militantes y simpatizantes 'populares' o ante auditorios nutridos (v. gr. la portada del 9 de marzo, o las fotografías que ilustran las crónicas de los días 13, 15, 20 y 24), mientras que Griñán suele aparecer solo o acompañado únicamente por algún dirigente de su partido (así, en la imagen publicada el día de arranque de la campaña, en la que el candidato espera solitario al pie de un autobús, o las de los días 10, 19, 20 y 21 de marzo).
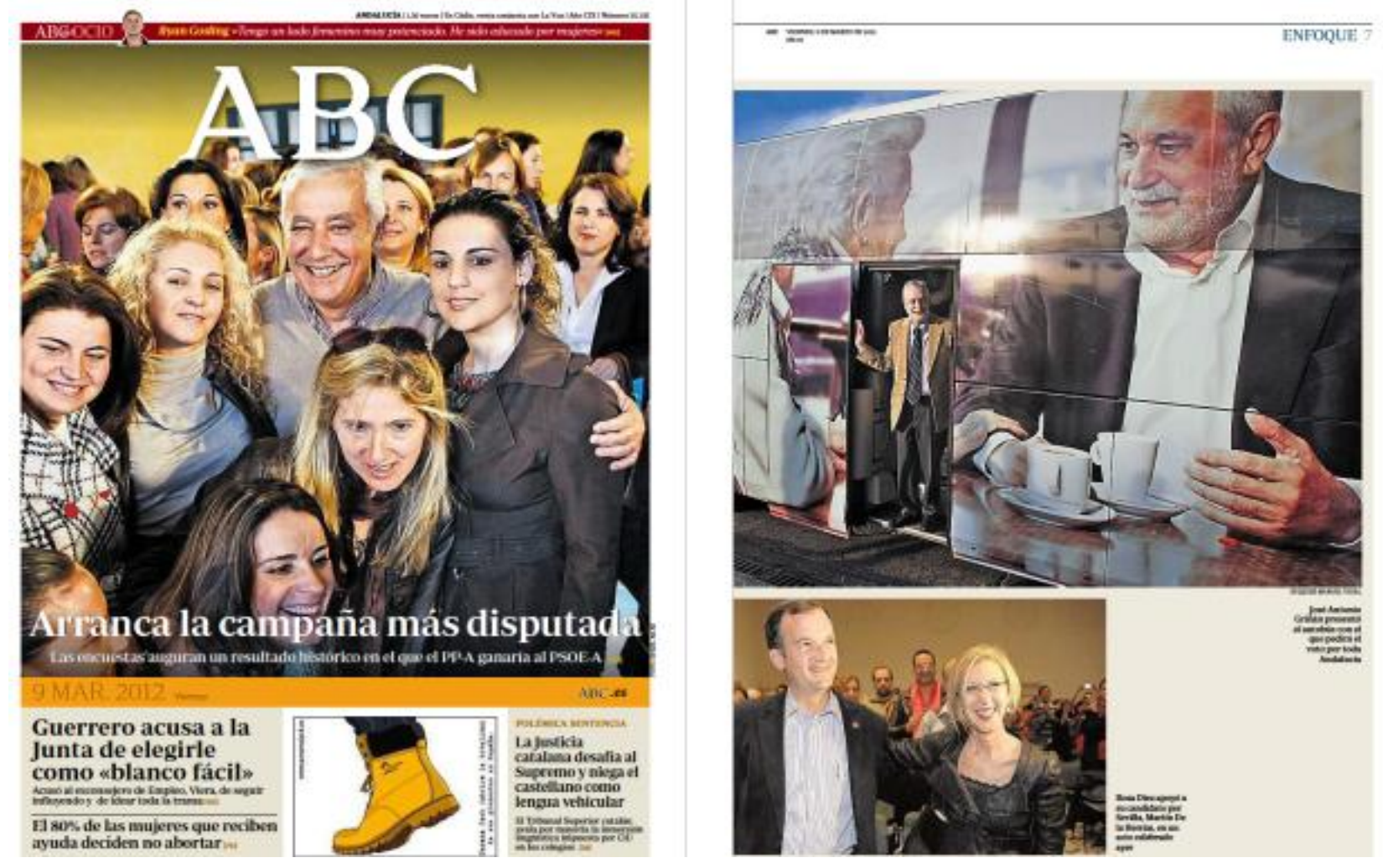

Figura 1. Portada y página interior de $A b c, 9$ de marzo de 2012.

Las fotografías de los dos líderes ofrecen idéntico perfil en El Mundo: Arenas rodeado de numerosos seguidores (vid. las informaciones de 9, 10, 13, 14 y 22 de marzo) frente a un Griñán mucho menos arropado (imágenes aparecidas los días 14, 15, 17 o 22) o con rostro de preocupación (11 de marzo). 
Revista Latina de Comunicación Social \# 068 - Páginas 268 a 289 Investigación financiada $\mid$ DOI: 10.4185/RLCS-2013-977 | ISSN 1138-5820| $\mid$ Año 2013

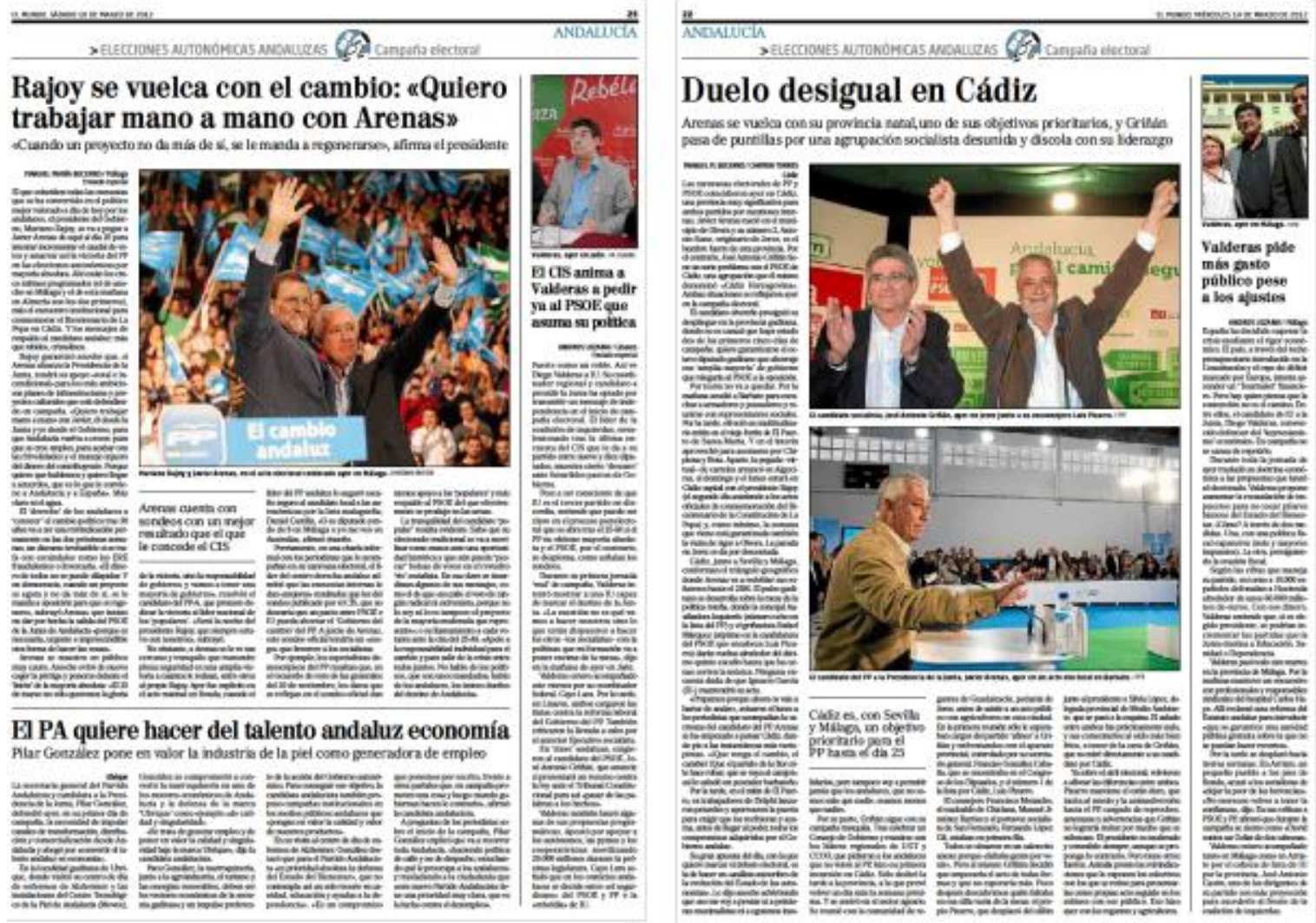

Figura 2. Páginas interiores de El Mundo, 10 y 14 de marzo de 2012

El contraste es menos evidente en el caso de El País, que ofrece instantáneas de los candidatos solos o acompañados casi en idéntica proporción.

\begin{tabular}{|l|c|c|c|c|c|c|c|c|}
\hline Tabla 13. Protagonista en elemento gráfico & \multicolumn{2}{|c|}{ Abc } & \multicolumn{2}{c|}{ ElMundo } & \multicolumn{2}{c|}{ EIPais } & \multicolumn{2}{c|}{ Tres diarios } \\
\cline { 2 - 9 } & $\begin{array}{c}\text { Total } \\
(\mathbf{n = 1 9 7 )}\end{array}$ & $\%$ & $\begin{array}{c}\text { Total } \\
(\mathbf{n = 1 5 5}\end{array}$ & $\%$ & $\begin{array}{c}\text { Total } \\
(\mathbf{n = 1 4 0 )}\end{array}$ & $\%$ & $\begin{array}{c}\text { Total } \\
(\mathbf{n = 4 9 2})\end{array}$ & $\%$ \\
\hline José Antonio Griñán & 39 & 19,8 & 29 & 18,7 & 26 & 18,6 & 94 & 19,1 \\
\hline Javier Arenas & 41 & 20,8 & 24 & 15,5 & 25 & 17,9 & 90 & 18,3 \\
\hline Diego Valderas & 9 & 4,6 & 17 & 11,0 & 16 & 11,4 & 42 & 8,5 \\
\hline Otros políticos & 1 & 0,5 & 23 & 14,8 & & & 24 & 4,9 \\
\hline Columnista & & & 8 & 5,2 & 7 & 5,0 & 15 & 3,0 \\
\hline Expertos & 1 & 0,5 & & & 10 & 7,1 & 11 & 2,2 \\
\hline Martín de la Herrán & 6 & 3,0 & 2 & 1,3 & 3 & 2,1 & 11 & 2,2 \\
\hline Mariano Rajoy & 6 & 3,0 & 3 & 1,9 & 1 & 0,7 & 10 & 2,0 \\
\hline Pilar González & 3 & 1,5 & 2 & 1,3 & 3 & 2,1 & 8 & 1,6 \\
\hline Manuel Chaves & 2 & 1,0 & 3 & 1,9 & & & 5 & 1,0 \\
\hline Cayo Lara & & & 2 & 1,3 & 3 & 2,1 & 5 & 1,0 \\
\hline Protagon. no cualificados & & & & & 5 & 3,6 & 5 & 1,0 \\
\hline Felipe González & 1 & 0,5 & 2 & 1,3 & 1 & 0,7 & 4 & 0,8 \\
\hline J. M. Sánchez Gordillo & & & 1 & 0,6 & 2 & 1,4 & 3 & 0,6 \\
\hline Alfredo. P. Rubalcaba & & & 1 & 0,6 & 2 & 1,4 & 3 & 0,6 \\
\hline M. Dolores de Cospedal & 1 & 0,5 & 1 & 0,6 & 1 & 0,7 & 3 & 0,6 \\
\hline Esteban de Manuel & & & & & 3 & 2,1 & 3 & 0,6 \\
\hline Ninguno & 111 & 56,3 & 67 & 43,2 & 54 & 38,6 & 232 & 47,2 \\
\hline
\end{tabular}


Los encuadres más habituales en las tres cabeceras son el estratégico y el de juego [tabla 14], pues ponen el énfasis en la crítica ejercida por los líderes y en sus argucias para obtener ventaja sobre el adversario, algo característico de la información electoral (Herrero y Benoit, 2009). Un 42,2 por ciento de las piezas se centra en el enfrentamiento dialéctico entre los cabezas de lista, en las diatribas que se dirigen unos a otros o en la competición entre candidatos reflejada en encuestas y debates televisivos.

Frente a esto, solo el 19,4 por ciento de las unidades de análisis se decanta por el enfoque temático. Las propuestas electorales, uno de los teóricos ejes de la campaña, únicamente se destacan en el 18,3 por ciento de los casos, y siempre en relación con el programa de gobierno del Partido Popular, lo cual apunta a un desinterés claro de los medios por esta parcela de la agenda política.

Por cabeceras, es $A b c$ la que en mayor medida adopta los encuadres estratégico y de juego en sus textos (46,7 por ciento), frente a El País, cuyo índice se sitúa en 37,8 .

\begin{tabular}{|l|c|c|c|c|c|c|c|c|}
\hline Tabla 14. Enfoque predominante y actividad destacada del protagonista \\
\hline & \multicolumn{2}{|c|}{ Abc } & \multicolumn{2}{c|}{ ElMundo } & \multicolumn{2}{c|}{ El Pais } & \multicolumn{2}{c|}{ Total } \\
\cline { 2 - 10 } & Total & $\%$ & Total & $\%$ & Total & $\%$ & Total & $\%$ \\
\hline Enfoques estratégico y de juego & 88 & 46,7 & 55 & 40,7 & 50 & 37,8 & 193 & 42,2 \\
\hline Respuesta/crítica al adversario & 77 & 39,1 & 50 & 32,3 & 42 & 30,0 & 169 & 34,3 \\
\hline Respuesta a los medios & 11 & 5,6 & 5 & 3,2 & 8 & 5,7 & 24 & 4,9 \\
\hline Aparición en encuesta & 3 & 1,5 & 8 & 5,2 & 2 & 1,4 & 13 & 2,6 \\
\hline Debate televisivo & 1 & 0,5 & & & 1 & 0,7 & 2 & 0,4 \\
\hline Enfoque temático & 40 & 18,3 & 40 & 20,6 & 29 & 19,3 & 110 & 19,4 \\
\hline Propuesta electoral & 31 & 15,7 & 32 & 20,6 & 27 & 19,3 & 90 & 18,3 \\
\hline Orgánica (partido) & 5 & 2,5 & & & & & 5 & 1,0 \\
\hline Ninguno & 69 & 35,0 & 60 & 38,7 & 61 & 42,9 & 189 & 38,4 \\
\hline Total & 197 & 100,0 & 155 & 100,0 & 140 & 100,0 & 492 & 100,0 \\
\hline
\end{tabular}

La línea editorial de los periódicos seleccionados - como es bien sabido, escorada hacia el PP las de Abc y El Mundo, y más afín a los socialistas la de El País (Canel, 1999)- se acaba trasluciendo en la actitud que adoptan redactores, corresponsales y articulistas en el tratamiento de la campaña [tabla 15], algo que no debe extrañar a tenor de la acusada politización del sistema de medios español (Hallin y Mancini, 2008: 104) [7].

Hay, sin embargo, matices de interés en esta práctica generalizada. El análisis ha permitido constatar que el 63,2 por ciento de los textos mantiene la apariencia de neutralidad, pues o bien no defiende de manera explícita a ningún candidato, o bien no rebate sus propuestas sin argumentación, o bien no asume acríticamente las afirmaciones hechas al calor de la campaña. En este sentido, El País presenta la mayor tasa de piezas que hemos caracterizado como neutrales (81,4 por ciento), frente a El Mundo $(43,9)$. El hecho de que este último acoja un elevado número de columnas -obligadas, por su naturaleza argumentativa, a tomar partido- ayuda a explicar este desfase en las proporciones.

\begin{tabular}{|l|c|c|c|c|c|c|c|c|}
\hline Tabla 15. Posicionamiento del periodista/medio \\
\cline { 2 - 9 } & \multicolumn{2}{|c|}{ Abc } & \multicolumn{2}{c|}{ ElMundo } & \multicolumn{2}{c|}{ EIPaís } & \multicolumn{2}{c|}{ Tres diarios } \\
\cline { 2 - 9 } & Total & $\%$ & Total & $\%$ & Total & $\%$ & Total & $\%$ \\
\hline Favorable & 18 & 9,1 & 17 & 11,0 & 8 & 5,7 & 43 & 8,7 \\
\hline Desfavorable & 50 & 25,4 & 70 & 45,2 & 18 & 12,9 & 138 & 28,0 \\
\hline Neutral & 129 & 65,5 & 68 & 43,9 & 114 & 81,4 & 311 & 63,2 \\
\hline Total & 197 & 100,0 & 155 & 100,0 & 140 & 100,0 & 492 & 100,0 \\
\hline
\end{tabular}


Pero llama la atención que en las tres cabeceras las críticas vayan dirigidas preferentemente a los partidos como ente colectivo en lugar de a los candidatos [tabla 16]. Así, en El Mundo son más habituales los textos poco favorables al PSOE (53) que los que ponen en duda las cualidades o la honradez de Griñán (10), y otro tanto ocurre con $A b c$ (la proporción en este caso es de 36 a 8), mientras que El País expresa sus reservas hacia el PP con mayor frecuencia que hacia Arenas (15 a 6). Del mismo modo, a la hora de defender una u otra opción, es habitual hacer referencia a la formación antes que al líder en El Mundo y El País, no así en Abc, más personalista en su discurso.

En el diario del grupo Prisa, la tendenciosidad se manifiesta sobre todo en el acriticismo con que se acogen las promesas socialistas (v. gr. "La enseñanza, un valor refugio", 16/03/2012), y en el afán por resaltar los apuros que pasa Arenas para defender su programa social frente a los recortes del Gobierno central (v. gr. "El escudo del 'legado terrible", 16/03/2012).

Por el contrario, El Mundo y Abc expresan abiertamente su apuesta por el Partido Popular, sobre todo en los artículos de opinión, apelando al mantra predilecto de Arenas durante toda la campaña, el del cambio: "El cambio es imprescindible en Andalucía" (El Mundo, 24/03/2012), "Los andaluces piden cambio" (Abc, 18/03/2012), "El cambio que necesita Andalucía" (Abc, 24/03/2012).

\begin{tabular}{|l|c|c|c|c|c|c|c|c|}
\hline \multirow{2}{*}{ Tabla 16. Posicionamiento del periodista/medio con respecto a partidos y candidatos } \\
\hline & \multicolumn{2}{|c|}{ Abc } & \multicolumn{2}{c|}{ El Mundo } & \multicolumn{2}{c|}{ ElPaís } & \multicolumn{2}{c|}{ Tres diarios } \\
\cline { 2 - 10 } & $\begin{array}{c}\text { Total } \\
(\mathbf{n = 1 9 7 )}\end{array}$ & $\%$ & $\begin{array}{c}\text { Total } \\
(\mathbf{n = 1 5 5})\end{array}$ & $\%$ & $\begin{array}{c}\text { Total } \\
(\mathbf{n = 1 4 0 )}\end{array}$ & $\%$ & $\begin{array}{c}\text { Total } \\
(\mathbf{n = 4 9 2})\end{array}$ & $\%$ \\
\hline Favorable & 18 & 100,0 & 17 & 100,0 & 8 & 100,0 & 43 & 100,0 \\
\hline PP & 5 & 27,8 & 15 & 88,2 & & & 20 & 46,5 \\
\hline Javier Arenas & 13 & 72,2 & 4 & 23,5 & & & 17 & 39,5 \\
\hline PSOE & & & & & 7 & 87,5 & 6 & 14,0 \\
\hline IU & & & & & 1 & 12,5 & 1 & 2,3 \\
\hline Desfavorable & 50 & 100,0 & 70 & 100,0 & 18 & 100,0 & 138 & 100,0 \\
\hline PSOE & 36 & 72,0 & 53 & 75,7 & & & 89 & 64,5 \\
\hline José Antonio Griñán & 8 & 16,0 & 10 & 14,3 & & & 18 & 13,0 \\
\hline PP & & & 2 & 2,9 & 15 & 83,3 & 17 & 12,3 \\
\hline IU & 6 & 12,0 & 6 & 8,6 & & & 12 & 8,7 \\
\hline Javier Arenas & & & & & 6 & 33,3 & 6 & 4,3 \\
\hline Manuel Chaves & 2 & 4,0 & & & & & 2 & 1,4 \\
\hline Diego Valderas & 2 & 4,0 & & & & & 2 & 1,4 \\
\hline Felipe González & 1 & 2,0 & & & & & 1 & 0,7 \\
\hline PA & & & 1 & 1,4 & & & 1 & 0,7 \\
\hline
\end{tabular}

\section{Conclusiones y discusión}

1. Con respecto a la cobertura de la campaña que cada diario practica, el cómputo de textos más abultado corresponde a $A b c$, seguido de El Mundo. Esto, unido al hecho de que ambas cabeceras dedican a los comicios más artículos de opinión que El País, demuestra que, en el caso de las elecciones andaluzas, su compromiso editorial -esto es, su afán por informar y, sobre todo, por trasladar al lector juicios que moldeen su visión de la realidad e influyan en su comportamiento- es mayor. 
2. Tanto El Mundo como Abc suelen destacar los leitmotivs de la campaña del Partido Popular -el escándalo de los ERE y la necesidad del cambio político en la Junta-, e incluso El País se ve obligado a incorporarlos aunque prefiera hacer hincapié en asuntos de alcance nacional. En este sentido, los tres diarios practican lo que Blumler y Gurevitch (1995) denominan "cobertura no reactiva", en la que las formaciones políticas introducen con facilidad su mensaje en los medios, ya sea por imposición o por convergencia de las agendas.

3. Nos encontramos ante una campaña dominada por un repertorio de temas limitado, carente de matices. Los propios diarios reconocen esta simplificación en el balance que realizan el mismo día de la votación: "Una campaña condicionada por los ERE" (El Mundo), "Los ERE marcan una campaña baja en proteínas" (El País).

4. En conjunto, la óptica regional se impone a lo largo de todo el proceso, beneficiada por la ausencia de comicios nacionales. Se confirma, por tanto, la primera hipótesis de nuestro trabajo. Sin embargo, durante la campaña no se presta atención a los problemas que aquejan a la comunidad autónoma (no olvidemos que Andalucía ostenta la mayor tasa de paro de todo el país [8], por citar solo el indicador más sangrante), sino que el discurso político -y por ende, el de los medios que lo hacen suyoatiende sobre todo a asuntos judiciales, con un propósito claramente electoralista.

5. El suministro de elementos de juicio es limitado en las tres cabeceras escogidas: hay escaso número de textos que proporcionen balances ecuánimes sobre la gestión del Gobierno andaluz durante los últimos cuatro años. Esto verifica nuestra segunda hipótesis.

6. Como era de esperar, la cobertura informativa centra el foco en los candidatos de los partidos mayoritarios, con escasa visibilidad de los cabezas de lista de las formaciones con menos expectativas electorales y de los líderes nacionales, sobre todo por lo que a la crónica de la campaña se refiere. En los artículos de opinión, sin embargo, suele criticarse con mayor frecuencia a los partidos que a los aspirantes a presidente.

7. La orientación ideológica de cada cabecera se deja sentir durante todo el periodo analizado, con nitidez aunque de forma no igualmente intensa: $A b c$ defiende explícitamente a su candidato preferido, Javier Arenas, en mayor número de ocasiones que el resto, mientras que El País y El Mundo optan preferentemente por la crítica al partido con el que no comulgan. El periódico dirigido por Javier Moreno es el más neutral en el tratamiento de la campaña.

8. Los encuadres predominantes en las tres cabeceras son el estratégico y el de juego, en detrimento del temático. Se privilegian el ataque al adversario, el enfrentamiento entre líderes y los elementos competitivos en lugar de las propuestas concretas de gobierno. De nuevo $A b c$ es el diario más destacado en este sentido, en contraposición a El País. Se confirma, de este modo, nuestra tercera hipótesis.

Sobre el efecto que la estrategia informativa adoptada por los medios seleccionados pudo tener entre el electorado, hemos de ser cautos por varias razones. La primera es que, en contra de todas las previsiones, el partido llamado a arrasar en los comicios finalmente cosechó una victoria exigua, insuficiente para gobernar, y ello a pesar de que logró imponer su agenda con claridad. La segunda es que la exposición a la prensa fue limitada por parte de los andaluces: tal y como revela una encuesta del CIS realizada un mes después de la cita electoral [9], la campaña suscitó poco interés entre el 29,5 por ciento de la población, y ninguno entre el 24; solo una proporción reducida, el 12,1 por ciento, la siguió de forma regular a través de los periódicos; y aunque hubo un 22,2 por ciento de votantes que esperaron hasta el final para decidir a qué partido apoyarían, hemos de suponer que en su mayoría extrajeron los elementos de juicio de los noticiarios de televisión, pues el 72,7 por ciento de los entrevistados aseguró haber recibido información electoral solo por este medio durante la última semana. 
Para terminar, y como complemento de nuestro trabajo, consideramos que resultaría interesante analizar el tipo de cobertura que se prestó a la campaña de las autonómicas andaluzas de 2008, celebradas al mismo tiempo que las generales, pues muy probablemente presentará elementos discordantes con la practicada en 2012.

Otra línea de investigación reveladora consistiría en diseccionar el seguimiento de la campaña efectuado por los medios audiovisuales, en especial la televisión, para determinar si existió confluencia de agendas y enfoques con la cobertura desplegada por la prensa.

* Este estudio forma parte de las investigaciones emprendidas en el marco del Proyecto de Excelencia SEJ-8073 "Credibilidad del sistema de medios en Andalucía. Confianza de la ciudadanía en los medios audiovisuales", financiado por la Consejería de Economía, Innovación y Ciencia de la Junta de Andalucía (Resolución de 13 de marzo de 2012).

\section{Bibliografía}

R Almaguer (2010): “Prensa diaria y elecciones: ¿contribución o seguimiento de la agenda?”, en Nieto, J. (ed.), Sociedad, desarrollo y movilidad en comunicación. Tamaulipas: Universidad Autónoma de Tamaulipas.

A Almazán, C Villarejo (1998): “Análisis del discurso de la prensa sobre las encuestas electorales en las elecciones generales de 1996”. Empiria, 1, Madrid, pp. 97-119.

J Benavides, MJ Canel (2003): "Los discursos de los medios, de los políticos y de los electores en la campaña electoral de 2000 ¿coherencia o contradicción?”, en I Crespo. (ed.), Las campañas electorales y sus efectos en la decisión de voto. Vol. II. Los resultados de la investigación. Valencia: Tirant Lo Blanch, pp. 295-310.

MR Berganza (2008a): “Medios de comunicación, 'espiral del cinismo’ y desconfianza política. Estudio de caso de la cobertura mediática de los comicios electorales europeos". Zer, vol. 13, núm. 25, Leioa, pp. 121-139.

MR Berganza (2008b): "Las elecciones al Parlamento Europeo como comicios de segundo orden. Estudio de la cobertura informativa en televisión (1999-2004)". Estudios sobre el Mensaje Periodístico, 14, Madrid, pp. 15-31.

MR Berganza; R de Miguel, MA Chaparro (2011): "La prensa gratuita ante las elecciones generales de España del 9 de marzo de 2008: cobertura, politización y frames en contraposición a la prensa de pago". Comunicación y Sociedad, vol. XXIV, núm. 1, Pamplona, pp. 35-61.

J Blumler, M Gurevitch (1995): The crisis of public communication. Nueva York: Routeledge.

MJ Canel (1997): "La objetividad periodística en campaña electoral: las actitudes profesionales de los periodistas de TVE1 y Antena 3 en las elecciones de 1996”. Zer, 2, Leioa, pp. 55-70.

MJ Canel (1999): “El País, Abc y El Mundo: tres manchetas, tres enfoques de las noticias”. Zer, 6, Leioa, pp. 91-117.

MJ Canel; J Benavides, N Echart (2003): "La campaña de 2000 en los medios de comunicación”, en I Crespo (ed.), Partidos, medios de comunicación y electores. Buenos Aires: Planeta, pp. 139179.

J Colmenarejo (2012): La aldea gala. Claves de un inesperado resultado electoral. Madrid: Sequitur. 
J Farré (1999): "Esfera pública, comunicación política y prensa diaria. La escenificación periodística de la campaña de las elecciones al Parlamento". Zer, 4, Leioa, pp. 89-109.

D Hallin, P Mancini (2008): Sistemas mediáticos comparados. Tres modelos de relación entre los medios de comunicación y la política. Barcelona: Hacer.

JC Herrero, WL Benoit (2009): "Análisis funcional de los debates en las elecciones generales de 2008”. Zer, vol. 14, núm. 26, Leioa, pp. 61-81.

ML Humanes (2009): "Nuevos temas noticiosos en las elecciones generales de 2004. La presencia de metacobertura en la prensa española”. Zer, vol. 14, núm. 26, Leioa, pp. 105-128.

JJ Igartua (2006): Métodos cuantitativos de investigación en comunicación. Barcelona: Bosch.

D Jackson (2011): "Strategic media, cynical public? Examining the contingent effect of strategic news frames on political cynicism in the United Kingdom". International Journal of Press/Politics, 16 (1), Londres, pp. 75-101.

HG Kavanag (1995): Election campaigning. The new marketing of politics. Oxford/Cambridge: USA Blackwell.

K Krippendorff (2002): Metodología de análisis de contenido: Teoría y práctica. Barcelona: Paidós.

M Martín, MR Berganza (2001): "Votantes y medios de comunicación en las elecciones nacionales españolas de 1996: ¿exposición selectiva o influencia mediática?”. Comunicación y Sociedad, vol. XIV, núm. 1, Pamplona, pp. 51-70.

P Norris et al. (1999): On message. Communicating the campaign. Londres: Sage Publications.

MÁ Novo (2007): “Comportamiento estratégico de los mass media y los partidos en campaña electoral. Una aproximación teórica". RIPS. Revista de Investigaciones Políticas y Sociológicas, vol. 6, núm. 1, Santiago de Compostela, pp. 43-52.

JF Paniagua, B Gómez (2006): “El control de la agenda mediática en campaña electoral: El caso de las elecciones generales españolas de 2004". Ámbitos, 15, Sevilla, pp. 283-296.

A Rivera (2012): El cortijo andaluz. Madrid: La Esfera de los Libros.

R Rodríguez (2004): Teoría de la agenda-setting. Aplicación a la enseñanza universitaria. Alicante: Obets.

V Sampedro, F Seoane (2008): "The 2008 Spanish general elections: "Antagonistic bipolarization" geared by presidential debates, partisanship, and media interests". The International Journal of Press/Politics, 13, Thousand Oaks, pp. 336-344.

JJ Sánchez (2005): “Análisis de contenido cuantitativo de medios”, en MR Berganza, JA Ruiz (coords.), Investigar en Comunicación. Madrid: McGraw Hill.

D Scheufele, D Tewksbury (2007): "Framing, Agenda Setting and Priming: The evolution of three media effects models". Journal of Communication, 57, Washington, pp. 9-20.

H Semetko, MJ Canel (1997): “Agenda-Senders vs Agenda-Setters: Television in Spain's 1996 election campaign”. Political Communication, vol. 14, núm. 4, Stanford, pp. 459-479.

D Weaver (2007): “Thoughts on Agenda Setting, Framing and Priming”. Journal of Communication, 57, Washington, pp. 142-147.

R Zugasti, P Lafuente (2010): "Los líderes políticos en la campaña de las elecciones europeas de 2009: un ejemplo de cobertura de comicios de segundo orden", en JM de Pablos (ed.), Actas 
del II Congreso Internacional Latina de Comunicación Social. La Laguna: Universidad de La Laguna.

C Zurutuza, C García (2012): "Las elecciones europeas de 2009 en la prensa aragonesa". Revista

Latina de Comunicación Social, 67, La Laguna, pp. 1-22:

http://www.revistalatinacs.org/067/art/945_Zaragoza/01_Cristina.html

DOI: 10.4185/RLCS-067-945-001-022 / CrossRef_link (13-mayo-2012 = fecha de consulta).

\section{Notas}

[1] Para un análisis detallado del desarrollo de la campaña electoral andaluza y el resultado de los comicios, vid. Colmenarejo (2012).

[2] Hay abundantes similitudes entre el segundo nivel de la agenda-setting y el framing, lo cual puede llevar a confundir ambos conceptos. Los dos se interesan fundamentalmente por el modo en que se abordan los temas de actualidad. Pero, tal y como apunta Weaver (2007: 145-146), el framing "does seem to include a broader range of cognitive processes -such as moral evaluations, casual reasoning, appeals to principles, and recommendations for treatment of problems- than does secondlevel agenda-setting (the salience of attributes of an object)".

[3] Fuente: www.ojd.es. Consulta realizada el 20 de diciembre de 2012.

[4] En la metacobertura, los medios tratan de desvelar la trastienda de la política, deconstruyendo púbicamente el discurso de los partidos, reflexionando sobre el proceso electoral y llamando la atención sobre la manipulación de la información (Humanes, 2009: 108).

[5] Solo en cuatro ocasiones arranca El Mundo con los comicios, coincidiendo con el inicio y el final de la campaña y la difusión de dos sondeos de opinión.

[6] De acuerdo con el barómetro del CIS correspondiente al mes en que se celebraron las elecciones (marzo de 2012), el paro era el principal motivo de preocupación para el 89,3 por ciento de los españoles, seguido de la situación económica (49,2 por ciento). Fuente:

http://www.cis.es/cis/opencm/ES/1_encuestas/estudios/ver.jsp?estudio=12684. Consulta realizada el 3 de noviembre de 2012.

[7] Sobre la politización de los medios españoles ante la información electoral, vid. Canel, 1997.

[8] La última Encuesta de Población Activa hecha pública antes de los comicios, correspondiente al cuarto trimestre de 2011, situaba el índice de desempleo de la comunidad en el 31,23 por ciento, muy por encima del 22,85 registrado a escala nacional. Fuente:

http://www.ine.es/daco/daco42/daco4211/epapro0411.pdf. Consulta realizada el 14 de noviembre de 2012.

[9] Fuente: http://www.cis.es/cis/opencm/ES/1_encuestas/estudios/ver.jsp?estudio=12844. Consulta realizada el 29 de octubre de 2012.

\section{Fuentes}

Abc. Edición Andalucía: 9-25 de marzo de 2012.

El Mundo. Edición Andalucía: 9-25 de marzo de 2012.

El País. Edición Andalucía: 9-25 de marzo de 2012.

Boletín OJD: núms. 318, 319 y 320 (septiembre, octubre y noviembre de 2012). 


\section{Revista Latina de Comunicación Social \# 068 - Páginas 268 a 289 Investigación financiada $\mid$ DOI: 10.4185/RLCS-2013-977 | ISSN 1138-5820| $\mid$ Año 2013}

Centro de Investigaciones Sociológicas. Barómetro Marzo 2012: http://www.cis.es/cis/opencm/ES/1_encuestas/estudios/ver.jsp?estudio=12684.

Centro de Investigaciones Sociológicas. Postelectoral Elecciones Autonómicas 2012 (Comunidad Autónoma de Andalucía): http://www.cis.es/cis/opencm/ES/1_encuestas/estudios/ver.jsp?estudio=12844.

Instituto Nacional de Estadística. Encuesta de Población Activa, cuarto trimestre de 2011: http://www.ine.es/daco/daco42/daco4211/epapro0411.pdf.

\section{CÓMO CITAR ESTE ARTÍCULO EN BIBLIOGRAFÍAS - HOW TO CITE THIS ARTICLE IN BIBLIOGRAPHIES / REFERENCES:}

BJ Gómez Calderón, FJ Paniagua Rojano, P Farias Batlle (2013): "Las elecciones autonómicas andaluzas de 2012 en la prensa nacional: Análisis de la cobertura de Abc, El Mundo y El País", en Revista Latina de Comunicación Social, 68. La Laguna (Tenerife): Universidad de La Laguna, páginas 268 a 289 recuperado el __ de ___ de $2 \ldots$ _ de http://www.revistalatinacs.org/068/paper/977_Malaga/11_Gomez.html DOI: 10.4185/RLCS-2013-977/CrossRef link

Artículo recibido el 24 de enero de 2013. Sometido a pre-revisión el 26 de enero. Enviado a revisores el 28 de enero. Aceptado el 7 de abril de 2013. Galeradas telemáticas a disposición de los autores el 12 de abril de 2013. Visto bueno de los autores: 13 de abril de 2013. Publicado el 15 de abril de 2013.

Nota: el DOI es parte de la referencia bibliográfica y ha de ir cuando se cite este artículo.

Autores:

\section{BJ Gómez Calderón}

ORCID = http://orcid.org/0000-0002-9245-9251

GS = http://scholar.google.es/citations?user=QJV5oDYAAAAJ bjgomez@uma.es

\section{FJ Paniagua Rojano}

ORCID = http://orcid.org/0000-0001-7376-4536

GS $=$ http://scholar.google.es/citations?user=9z8ZuMMAAAAJ fjpaniagua@uma.es

\section{P Farias Batlle}

ORCID = http://orcid.org/0000-0002-9634-5198

GS $=$ http://scholar.google.es/citations?user=jfBzHdMAAAAJ

farias@uma.es 